\section{University of New Hampshire}

Carsey School of Public Policy

\section{CARSEY RESEARCH}

National Issue Brief \#102

Summer 2016

\title{
Fewer Than Half of WIC-Eligible Families Receive WIC Benefits
}

Kristin Smith

$\mathrm{T}$ The Special Supplemental Nutrition Program for Women, Infants, and Children (WIC) serves millions of low-income women, infants, and children who are at nutritional risk by providing checks or vouchers for nutritious foods, nutrition counseling, breastfeeding support, and health care referrals. ${ }^{1}$ Foods eligible for WIC are high in certain nutrients and designed to meet the special nutritional needs of lowincome pregnant, breastfeeding, or postpartum women, as well as infants and children up to age $5 .^{2}$

Research has shown that WIC is a successful and cost-effective program. Numerous studies find that WIC participation improves pre- and postnatal health outcomes; families' overall nutrition; access to prenatal care, health care for children, and immunizations; and children's cognitive development and academic achievement. ${ }^{3}$

In 2015, the average monthly WIC benefit was $\$ 43.58$ per person. Easing the costs associated with buying nutritional foods frees up family resources for other necessities, like housing and medical costs. Families with pre-tax incomes up to 185 percent of the federal poverty line are eligible for the program. ${ }^{4}$ WIC benefits are especially important for rural families, as the poverty rate is higher in rural than in urban areas (18 percent compared with 15 percent in 2014). ${ }^{5}$ It is important to consider uptake differences by place type as research indicates that rural women perceive more stigma surrounding participation in government assistance programs compared with women in urban areas. ${ }^{6}$

Despite these important benefits, fewer than half of families eligible for WIC benefits received them in 2014. ${ }^{7}$ This analysis uses data from the 2015 Current Population Survey and identifies the characteristics of nonparticipating WIC-eligible families to highlight populations that could be targeted and thereby increase the reach of WIC.

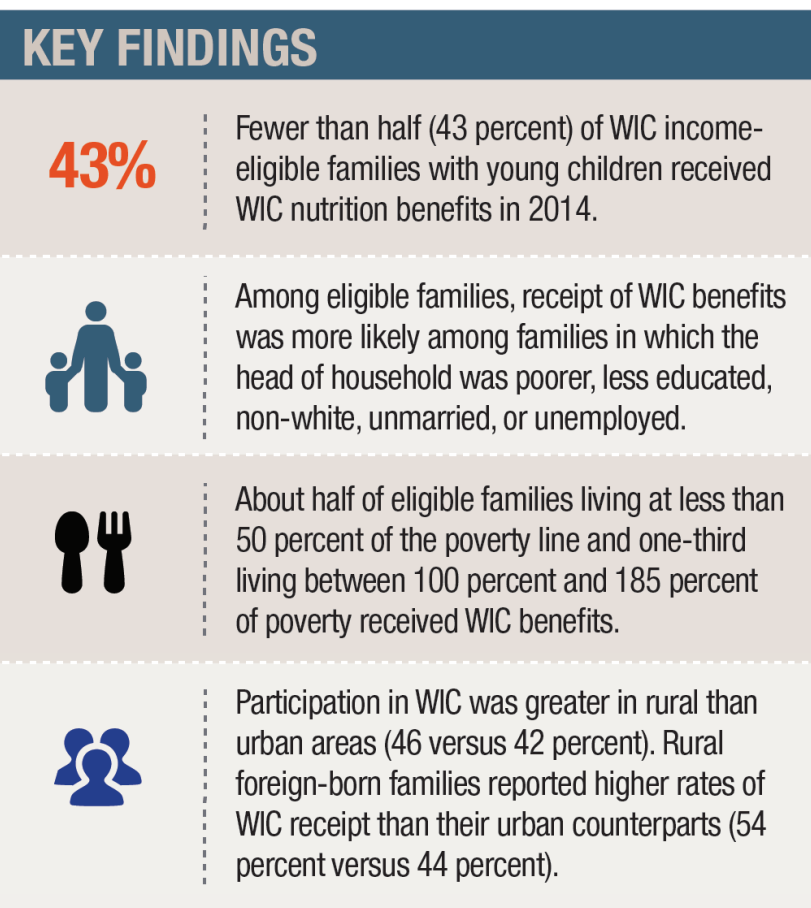

Since 1997 WIC has been "fully funded," meaning that it has received sufficient resources to serve all eligible individuals who apply and has not needed to turn away eligible applicants due to funding constraints. ${ }^{8}$ Preliminary estimates from the U.S. Department of Agriculture Food and Nutrition Service, which runs the program at the federal level, show that WIC served 8 million participants during each month of 2015, with the majority of recipients being infants and children. ${ }^{9}$ According to the Food and Nutrition Service, the fiscal year 2016 total WIC budget is $\$ 6.7$ billion, an amount consistent with previous budgets and enough to service the projected 8.5 million individuals expected to participate each month. ${ }^{10}$ 


\section{Who Receives WIC Benefits Among WIC- Eligible Families?}

Just 43 percent of families eligible for WIC benefits received them in 2014 (Table 1). The rate for rural families (46 percent) was slightly higher than for urban families (42 percent), despite potentially greater barriers to WIC participation in rural areas. The higher WIC receipt in rural areas may be due to the fact that WIC-eligible families reported lower income in rural areas than in urban areas, signaling greater disadvantage (data not shown).

By region, WIC receipt among WIC eligible families was similar in rural places except that a smaller proportion of eligible rural families in the Midwest received WIC compared with families in the West (Figure 1). Urban areas also reported similar WIC receipt among WIC eligible families across regions, except that urban WIC eligible families in the Northeast were less likely to receive WIC than families in the West. Reported WIC receipt was higher in the rural South compared with the urban South.

\section{Box 1: Defining WIC-Eligible} Families

WIC-eligible families in this analysis include those with incomes less than 185 percent of poverty, who have a child under 5 in the household, and have a householder 18 or older. Due to data limitations, pregnant and breastfeeding women who may be eligible are not included unless they reside with an eligible child. Additionally, foster children who do not live in a WIC-eligible family with young children are excluded from this analysis.

\section{TABLE 1. PERCENTAGE OF WIC-ELIGIBLE FAMILIES RECEIVING WIC BENEFITS, BY PLACE, 2014}

\begin{tabular}{|c|c|c|c|}
\hline & ALL & R URAL & URBAN \\
\hline WIC receipt am ong WIC-eligible families & 42.8 & 45.8 & 42.1 * \\
\hline \multicolumn{4}{|l|}{ Poverty } \\
\hline Less than $50 \%$ of poverty & 50.6 & 54.3 & 49.6 \\
\hline $50 \%$ to $100 \%$ of poverty & 46.8 & 54.4 & 45.7 * \\
\hline $100 \%$ to $185 \%$ of poverty & 35.9 & 36.0 & 35.7 \\
\hline \multicolumn{4}{|l|}{ Marital status } \\
\hline Married & 39.7 & 42.6 & 39.1 \\
\hline Previously married & 38.6 & 45.8 & 37.1 * \\
\hline Never married & 48.0 & 49.7 & 47.4 \\
\hline \multicolumn{4}{|l|}{ Education } \\
\hline Less than high school & 50.9 & 49.1 & 51.1 \\
\hline High school & 42.8 & 44.3 & 42.5 \\
\hline Some college & 43.3 & 50.5 & 41.7 * \\
\hline College graduate & 22.6 & 22.7 & 22.2 \\
\hline
\end{tabular}

Note: All data are weighted. Characteristics refer to the householder. All estimates restricted to householders age 18 or older. Due to data limitations, pregnant and breastfeeding women who may be eligible for WIC are not included unless they reside with an eligible child. WIC eligibility income criteria is $185 \%$ of poverty; poverty measures use official poverty definition. * Indicates statistically significant difference $(p<.05)$ between rural and urban. Source: Estimates from the Current Population Survey's 2015 Annual Social and Economic Supplement.

In terms of income, WIC receipt was lower among eligible families with higher incomes (Table 1). Despite being eligible for the program, only about one-third of families living between 100 percent and 185 percent of poverty reported WIC receipt, compared to about half of households living at less than 50 percent of poverty or living between 50 percent and 100 percent of poverty. Within rural and urban areas, similar proportions of families living at less than 50 percent of poverty and between 100 percent and 185 percent of poverty received WIC benefits, but receipt was higher in rural than in urban areas among eligible households living at 50 to 100 percent of poverty.

\section{WIC Receipt Less Likely in White Than in Black or Hispanic Eligible Families}

Eligible white families were less likely to receive WIC benefits than black or Hispanic families in both rural and urban areas (Figure 2). ${ }^{11}$ For example, among rural families eligible for WIC, 40 percent of white, non-Hispanic families received benefits, compared to 60 percent of black, non-Hispanic families and 57 percent of Hispanic families. WIC programs in rural areas appear to have more successfully attracted minority populations than programs in urban areas, as rates of WIC receipt were 
FIGURE 1. PERCENTAGE OF WIC-ELIGIBLE FAMILIES RECEIVING WIC BENEFITS, BY REGION AND PLACE, 2014

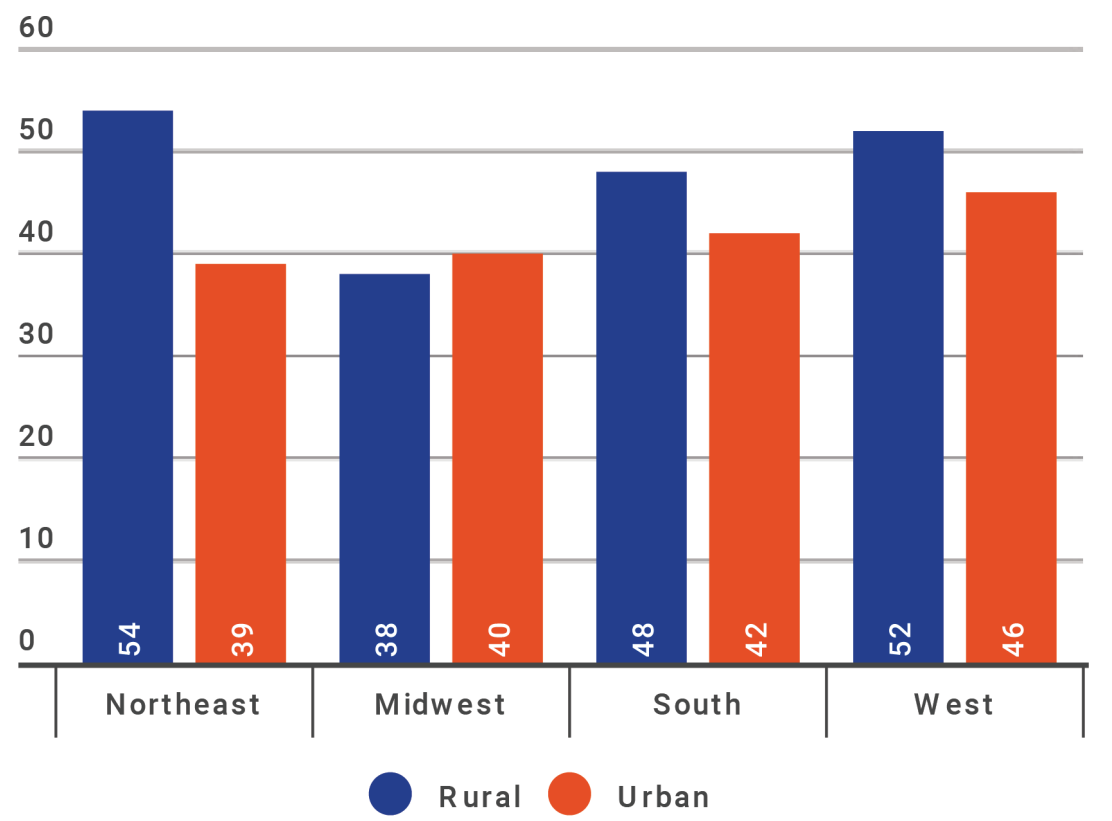

Note: All data are weighted. Characteristics refer to the householder. All estimates restricted to householders age 18 or older. Due to data limitations, pregnant and breastfeeding women who may be eligible for WIC are not included unless they reside with an eligible child. WIC eligibility income criteria is $185 \%$ of poverty; poverty measures use official poverty definition.

Source: Estimates from the Current Population Survey's 2015 Annual Social and Economic Supplement.

\section{FIGURE 2. PERCENTAGE OF WIC-ELIGIBLE FAMILIES RECEIVING WIC BENEFITS, BY RACE AND PLACE, 2014}

60

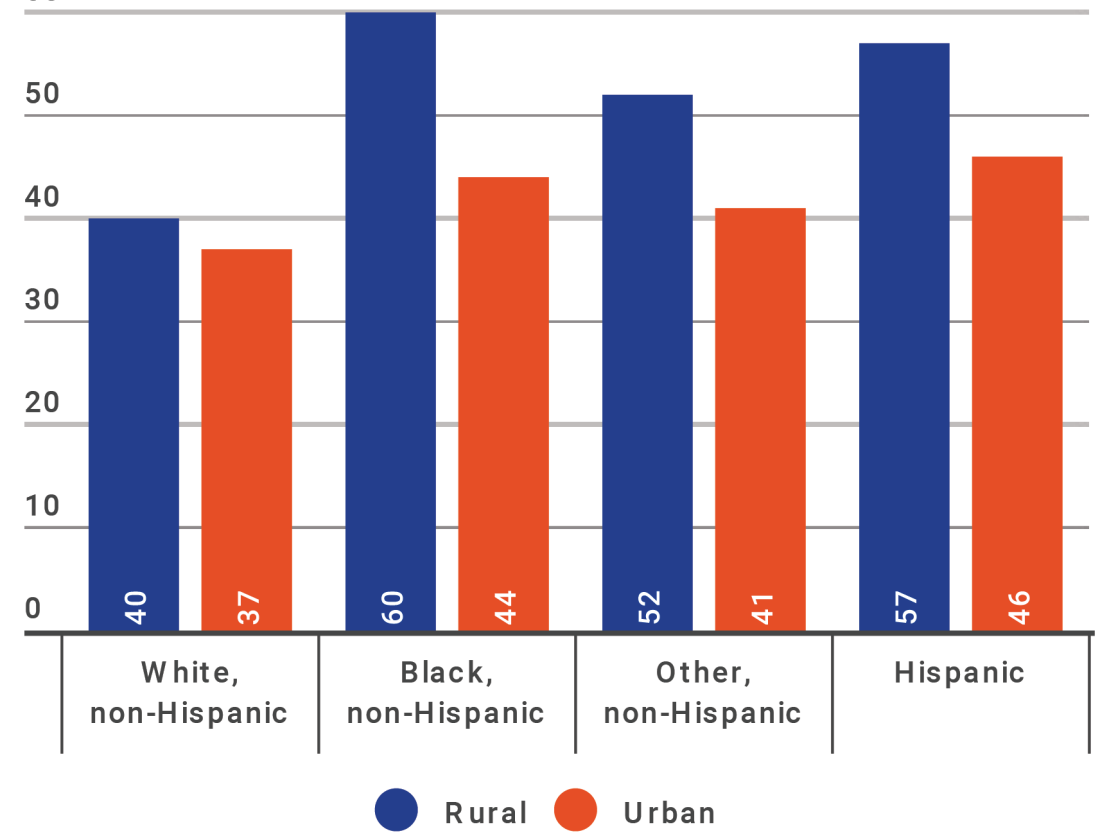

Note: All data are weighted. Characteristics refer to the householder. All estimates restricted to householders age 18 or older. Due to data limitations, pregnant and breastfeeding women who may be eligible for WIC are not included unless they reside with an eligible child. WIC eligibility income criteria is $185 \%$ of poverty; poverty measures use official poverty definition.

Source: Estimates from the Current Population Survey's 2015 Annual Social and Economic Supplement. substantially higher among blacks, Hispanics, and other races in rural compared to urban areas. Whites were equally likely to receive WIC benefits in rural and urban areas.

Rural foreign-born families reported higher rates of WIC receipt than their urban counterparts (54 percent and 44 percent, respectively; see Figure 3). ${ }^{12}$ WIC receipt was similar among U.S.born and native born families in both rural and urban areas.

\section{Family Structure Differences in WIC Receipt}

In urban areas, WIC receipt was highest among families with a parent who had never married compared with families with a married or previously married parent (Table 1). In rural areas, the pattern was somewhat different, as married- and single-parent families had similar rates of WIC receipt. WIC receipt was higher among families with a previously married parent in rural areas (46 percent) compared with urban areas (37 percent).

Since food expenses are greater in families with more children, one might expect WIC-eligible families with more children to have higher WIC receipt. This pattern is borne out in urban areas; however, among rural families eligible for WIC, receipt was similar regardless of the number of children (Figure 4). WIC receipt is higher among rural than urban families with three or more children present. 


\section{FIGURE 3. PERCENTAGE OF WIC-ELIGIBLE FAMILIES RECEIVING WIC BENEFITS, BY IMMIGRANT STATUS AND PLACE, 2014}

60

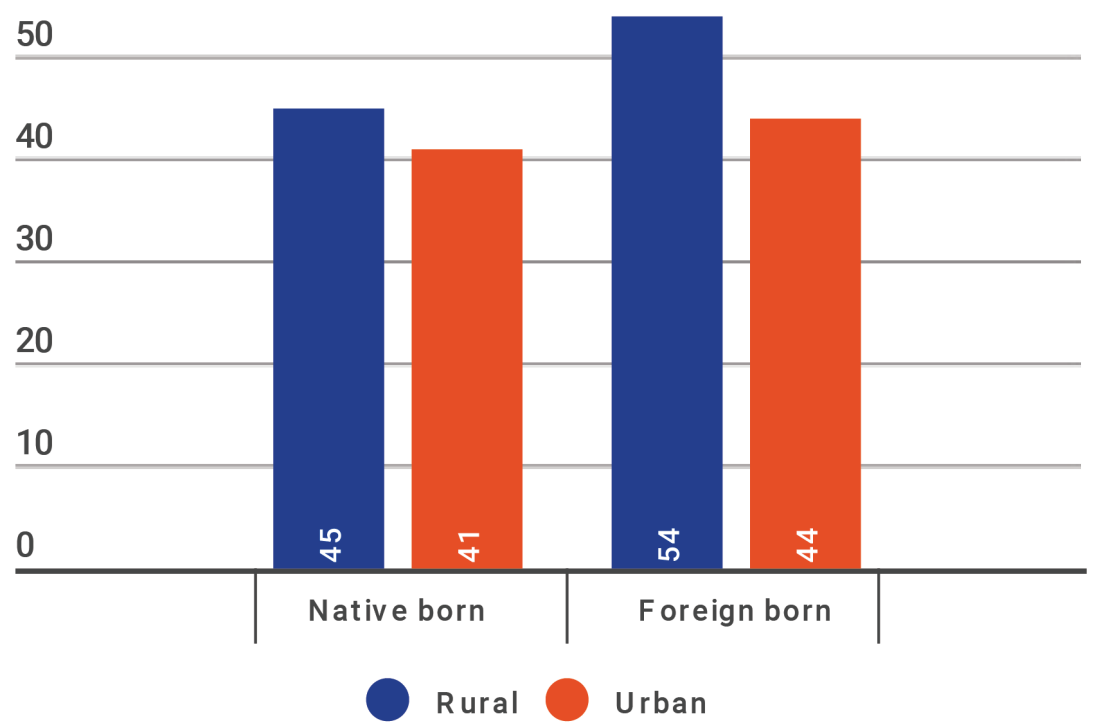

Note: All data are weighted. Characteristics refer to the householder. All estimates restricted to householders age 18 or older. Due to data limitations, pregnant and breastfeeding women who may be eligible for WIC are not included unless they reside with an eligible child. WIC eligibility income criteria is $185 \%$ of poverty; poverty measures use official poverty definition.

Source: Estimates from the Current Population Survey's 2015 Annual Social and Economic Supplement.

\section{FIGURE 4. PERCENTAGE OF WIC-ELIGIBLE FAMILIES RECEIVING WIC BENEFITS, BY NUMBER OF CHILDREN UNDER 5 AND PLACE, 2014}

60

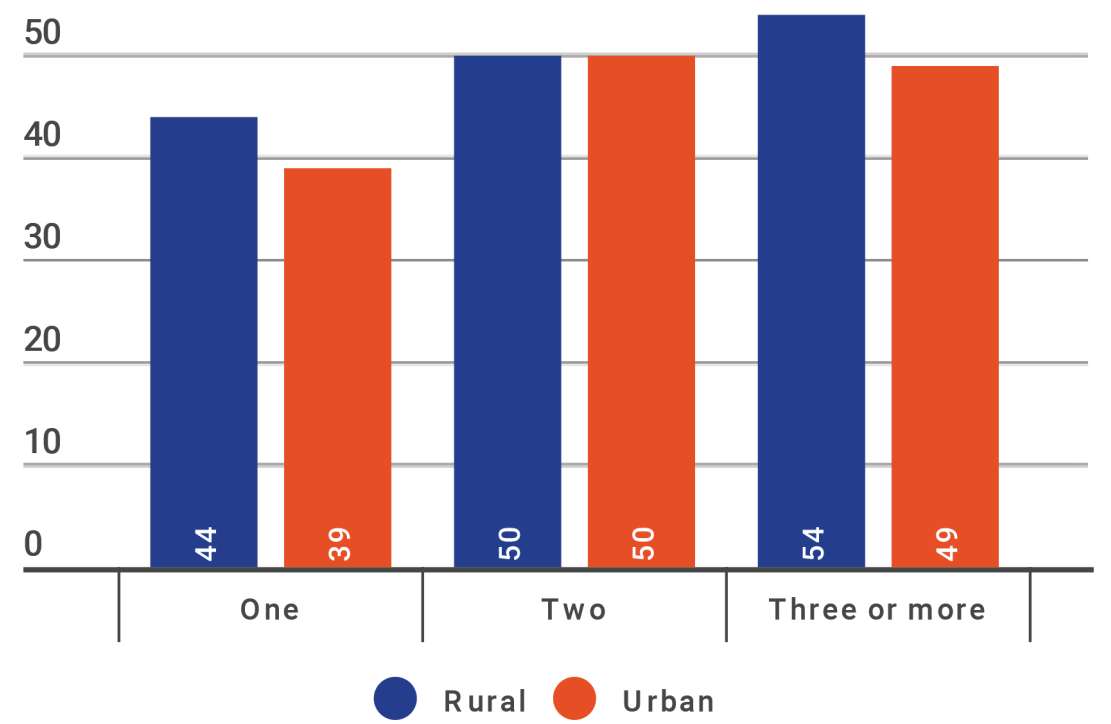

Note: All data are weighted. Characteristics refer to the householder. All estimates restricted to householders age 18 or older. Due to data limitations, pregnant and breastfeeding women who may be eligible for WIC are not included unless they reside with an eligible child. WIC eligibility income criteria is $185 \%$ of poverty; poverty measures use official poverty definition.

Source: Estimates from the Current Population Survey's 2015 Annual Social and Economic Supplement.
WIC Receipt Is Higher at Lower Levels of Education and Among the Unemployed

WIC receipt was generally higher among those with lower levels of education in both rural and urban areas (Table 1). ${ }^{13}$ However, those with some college education were just as likely to receive WIC as those with less than a high school degree in urban areas. Rates of WIC receipt were low (approximately 23 percent) among both rural and urban WICeligible families with college degrees. Low WIC receipt among the highly educated might be expected due to the link between education level and higher income, though one might expect higher WIC receipt among the eligible college educated as they may have more knowledge about government programs. However, there may be confusion among this group about eligibility criteria, reluctance to accept government assistance due to stigma, or fear of mistreatment by program staff or grocery store cashiers. ${ }^{14}$

In both rural and urban areas, WIC-eligible families with an unemployed householder reported higher rates of WIC receipt than those who were employed and those not in the labor force (that is, those who are voluntarily not working, or who have dropped out of the labor force; see Figure 5). In contrast, in urban areas families with an unemployed householder reported higher levels of WIC receipt than those who were employed, but similar levels as those who were not in the labor force. Among those not in the labor force, a higher proportion living in rural areas reported WIC receipt than those living in urban areas. 


\section{FIGURE 5. PERCENTAGE OF WIC-ELIGIBLE FAMILIES RECEIVING WIC BENEFITS, BY EMPLOYMENT STATUS AND PLACE, 2014}

60

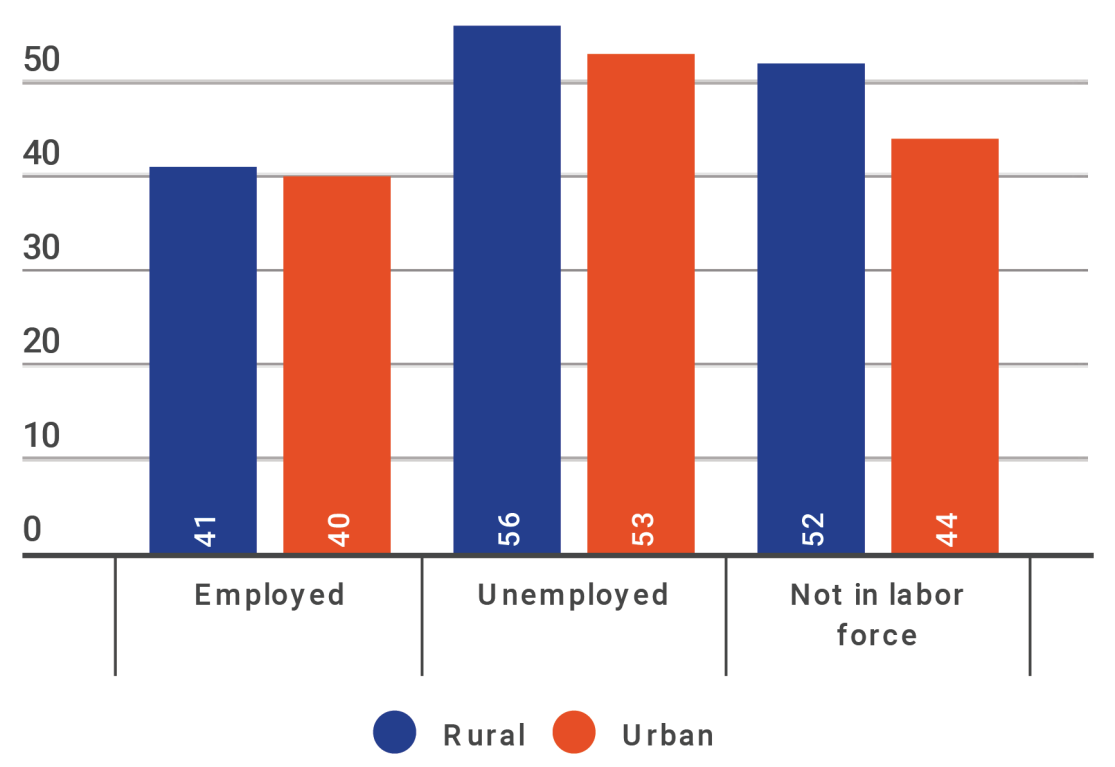

Note: All data are weighted. Characteristics refer to the householder. All estimates restricted to householders age 18 or older. Due to data limitations, pregnant and breastfeeding women who may be eligible for WIC are not included unless they reside with an eligible child. WIC eligibility income criteria is $185 \%$ of poverty; poverty measures use official poverty definition.

Source: Estimates from the Current Population Survey's 2015 Annual Social and Economic Supplement.

\section{Conclusion}

This analysis shows that families most in need of WIC assistance are more likely to receive it. For example, WIC receipt is higher among the poor, the less educated, the unemployed, the unmarried, or those with multiple children.

Among those eligible for but not receiving WIC benefits are families living above the official poverty line but below $185 \%$ of poverty, a group typically considered low income and often eligible for other government programs. In addition, only 37 percent of white families eligible for WIC receive it. Policy makers and service providers looking to expand the reach of WIC could target these populations.
There are a number of hurdles to participation in government assistance programs such as WIC, including psychological barriers (social stigma), structural barriers (lack of transportation), bureaucratic complications (arduous application processes), and financial costs (missed work when applying for the program). ${ }^{15}$ Research on the Temporary Assistance for Needy Families program has found that rural women feel more stigma surrounding participation in government assistance programs compared with women in urban areas, ${ }^{16}$ and stigma is cited as a major barrier to WIC participation among qualifying women with relatively higher income. ${ }^{17}$ Those who are employed or have a college education may view participation in a government assistance program unfavorably. Also, lack of knowledge of eligibility requirements may deter eligible recipients from applying. For example, new parents may not be aware of the WIC program, or may not know if they are eligible. Finally, family income may vary from month to month as family members gain and lose employment or work hours fluctuate, perhaps leading some to question the usefulness of applying to the program. ${ }^{18}$

Policy makers can expand WIC's role as a safety net for lowincome families and spread the reach of WIC, thereby expanding the positive nutritional, health, and cognitive benefits for women and children. However, the WIC budget would need to increase in order to meet the increased demand. Without additional funds, an increase in applications could result in a waiting list.

WIC is an important safety net program that successfully provides nutritious foods, nutrition counseling, breastfeeding support, and health care referrals, and it has a proven record of improving health outcomes, cognitive development, and educational attainment for children. Expanding the reach of WIC to all eligible families could benefit families struggling to make ends meet. 


\section{Data}

The data in this brief come from the 2015 Annual Social and Economic Supplements (ASEC) of the Current Population Survey (CPS). The CPS is a joint project between the Bureau of Labor Statistics and the U.S. Census Bureau. The CPS provides a nationally representative sample of approximately 50,000 households and the individuals in those households, and collects demographic, economic, and employment information, as well as information on participation in select government assistance programs. The ASEC supplement analyzed here was conducted in the spring of 2015 (released with the March CPS data) and was obtained from the IPUMS files compiled by the Minnesota Population Center at the University of Minnesota (www.ipums.org).

The question analyzed in this brief refers to WIC receipt in 2014. The CPS questionnaire asks respondents whether, "At any time in the last year, (were you/was anyone in this household) on WIC, the Women, Infants, and Children Nutrition program?" Thus, the WIC receipt question analyzed in this brief is self-reported from a single household respondent (that is, the householder). Throughout this brief we use the term "family" for ease of composition, even though the analysis is done at the household level. It is possible that these estimates underreport the receipt of WIC if the respondent is unaware of other household members' WIC receipt. Questions about earnings and income also refer to 2014. All analyses are weighted using household-level weights provided by the Census Bureau. Differences presented in the text are statistically significant $($ at $\mathrm{p}<.05)$.

\section{Endnotes}

1. Food and Nutrition Service, "Women, Infants and Children (WIC)" (Washington, DC: U.S. Department of Agriculture, 2015); Steven Carlson, Zoe Neuberger, and Dottie Rosenbaum, "WIC Participation and Costs Are Stable: Have Returned to Pre-Recession Levels" (Washington, DC: Center on Budget and Policy Priorities, 2015).

2. Eligible foods include breakfast cereal, infant cereal/fruits/vegetables/ meat (that is, baby food), infant formula, milk, cheese, tofu, soy milk, beans, peanut butter, fruits and vegetables, canned fish, whole grain breads, juice, eggs, and medical foods (for those with special dietary needs). See Food and Nutrition Service, "WIC Eligible Foods" (Washington, DC: U.S. Department of Agriculture, 2015).

3. Food and Nutrition Service, "About WIC: How WIC Helps" (Washington, DC: U.S. Department of Agriculture, 2015); Steven Carlson and Zoe Neuberger, "WIC Works: Addressing the Nutrition and Health Needs of Low-Income Families for 40 Years" (Washington, DC: Center on Budget and Policy Priorities, 2015), http:// cbpp.org/wicworks.

4. In addition to income eligibility, the applicant must be a state resident and be determined to be nutritionally at-risk by a health care provider. Pregnant and lactating women within the income eligibility are also eligible for WIC. All foster children under age 5 , regardless of household income, are eligible for WIC. See Food and Nutrition Service, "Frequently Asked Questions About WIC" (Washington, DC: U.S. Department of Agriculture, 2015).

5. "Rural Poverty and Well-Being" (Washington, DC: U.S. Department of Agriculture, 2015), http://www. ers.usda.gov/topics/rural-economypopulation/rural-poverty-well-being/ poverty-overview.aspx.
6. K. McCormack, "Resisting the Welfare Mother: The Power of Welfare Discourse and Tactics of Resistance," Critical Sociology 30 (2004): 355-83.

7. Regardless of eligibility, it is worth noting that only a very small minority of U.S. households receive WIC benefits: in 2014, 4 percent of rural and 3 percent of urban households reported that someone in the household received WIC. A study conducted by the U.S. Department of Agriculture found that WIC served about 63 percent of all eligible women, infants, and children in 2012. The estimates presented here differ from the USDA estimates because this study analyzed data at the family level, whereas the USDA study analyzed data at the individual level.

8. The number of families that can receive WIC benefits depends on the annual appropriation; if more families apply for WIC than the funding can support, the program institutes a waiting list and does not serve all applicants. The WIC program operates differently than the Supplemental Nutrition Assistance Program (SNAP), which is an "entitlement" program with a budget that will automatically expand to ensure that all eligible applicants receive benefits. See Carlson, Neuberger, and Rosenbaum (2015) for details.

9. Food and Nutrition Service, "WIC Program” (Washington, DC: U.S. Department of Agriculture, 2016), http:// www.fns.usda.gov/pd/wic-program.

10. Food and Nutrition Service, "Total WIC Budget for Fiscal Year 2016" (Washington, DC: U.S. Department of Agriculture), http://www.fns.usda.gov/ wic/wic-funding-and-program-data.

11. In this analysis, the race and ethnicity of the family is denoted by the race and ethnicity of the householder.

12. In this analysis, the nativity status of the family is denoted by the nativity of the householder. 
13. In this analysis, the education level of the family is denoted by the education level of the householder.

14. Carol Bryant, et al., "A Social Marketing Approach to Increasing Enrollment in a Public Health Program: A Case Study of the Texas WIC Program," Human Organization 60, no. 3 (2001): 234-46.

15. L. Powell, J. Amsbary, and H. Xin, "Stigma as a Communication Barrier for Participation in the Federal Government's Women, Infants, and Children Program," Qualitative Research Reports in Communication 16, no. 1 (2015): 75-85; P.G. Scottand and S.K. Pandey, "The Influence of Red Tape on Bureaucratic Behaviors: An Experimental Simulation," Journal of Policy Analysis and Management 19, no. 4 (2000): 615-33.

16. McCormack (2004).

17. Powell, Amsbary, and Xin (2015).

18. The certification period for WIC varies depending on whether the individual is pregnant, postpartum, breastfeeding, an infant, or a child. An eligible individual usually receives WIC benefits from six months to a year, at which time she/he must reapply.

\section{About the Author}

Kristin Smith is a family demographer at the Carsey School of Public Policy and research associate professor of sociology at the University of New Hampshire (kristin.smith@ unh.edu).

\section{A ck n ow ledg ments}

This brief was funded by anonymous donors. The author thanks Jessica Carson, Marybeth Mattingly, Michael Ettlinger, Curt Grimm, Michelle Dillon, Amy Sterndale, Laurel Lloyd, and Bianca Nicolosi at the Carsey School of Public Policy and Patrick Watson for substantive comments and editorial contributions. 


\section{University of New Hampshire Carsey School of Public Policy}

The Carsey School of Public Policy at the University of New Hampshire is nationally recognized for its research, policy education, and engagement. The school takes on the pressing issues of the twenty-first century, striving for innovative, responsive, and equitable solutions.

Huddleston Hall • 73 Main Street • Durham, NH 03824

(603) 862-2821

TTY UsERS: DIAL 7-1-1 OR 1-800-735-2964 (RELAY N.H.)

carsey.unh.edu 